\title{
Editorial for Journal of Packaging Technology and Research
}

\author{
N. C. Saha ${ }^{1}$
}

Published online: 2 April 2019

(C) Indian Institute of Packaging 2019

I have a great pleasure to present the first issue of third year of publication of this journal of Packaging Technology and Research (Volume 3. Number 1) which has been able to establish its popularity among the researchers in the field of Packaging Science and Technology within a period of 3 years. I do recall about the publication of our launch issue in March, 2017 while the number of research paper in this particular field was very limited. But it is amazing to note that within a very short period of time, the response of research paper from the researchers for this journal has been increased substantially. Moreover, numbers of reviewers are also increasing day by day who are showing their keen interests to be associated to this journal for the review of research papers.

The main reason could be the kind of effort is being taken by our publishers for making its popularity among the young researchers. The researchers do find the publications on this journal are diversified in nature by way of covering wide range of topics like innovative materials for packaging applications, characteristics behaviour of different types of packaging materials ranging from paper, paper board, plastic films and laminates, Plastic based rigid containers, bio degradable film, bio based polymeric materials, Corrugated fibre board boxes etc., Product- Package Compatibility, Shelf life study of different types of food products including of fresh fruits and vegetables, meat, fish, poultry and also processed food products, package design and the effect of different types of packaging systems like retort packaging, Vacuum and gas flushing technique, active packaging, Modified Atmosphere Packaging etc. to enhance the shelf life of food products.

This particular issue covers different topics like preparation and Characterisation of a Biodegradable Film comprising Polyvinyl Alcohol in Balangu Seed Gum, Development and Evaluation of Pilot Scale Modified Atmosphere Storage

\footnotetext{
N. C. Saha

director-iip@iip-in.com

1 Indian Institute of Packaging, Mumbai, India
}

and Modified Atmosphere Packaging Systems for Tomatoes, Effect of Chitosan-Beeswax Edible Coatings on the Shelflife of Sapodilla (Achras Zapotec) fruit,Prediction of Some Physical Attributes of Cassava Starch-Zinc Nanocomposite Film for Food Packaging applications, Effect of Vacuum and Active Packaging on the Biochemical and Microbial Quality of Indian Oil Sardine (Sardinella longiceps) during Iced Storage, Moisture Sorption Isotherm Modelling Approach and Effect of Packaging Material on Quality Changes in Extruded Product Stored Under Controlled Conditions, Preparation and Characterization of Nano Sized Sr1-xAgx TiO3 System as Antimicrobial Nanomaterial Coating for Paper Base Packaging Materials and Application of Biodegardable Polymers in Food Packaging Industry: A Comprehensive Review.It is expected that the different topics covered in this issue of this journal will be highly useful for the researchers who would find relevant for their research work.

In fact, the journal of Packaging Technology and Research (JPAC) is an international peer-reviewed publication that publishes original, high quality research papers and review articles on topics related to Packaging Science and Technology. In addition to original and review articles and an attempt is also taken to include an exclusive section under the title of "Industry News" to highlight in packaging innovations and patents and offerings which do come from packaging industry.

I invite the researchers working on different aspects of Packaging research to contribute to JPAC. To submit online or to read papers published so far free of Charge, please visit the journal webpage at http://w.w.w.springer.com/engineerin g/industrial+Management/journal/41783.

Publisher's Note Springer Nature remains neutral with regard to jurisdictional claims in published maps and institutional affiliations. 